\title{
DERECHOS HUMANOS DE PERSONAS PRIVADAS DE LA LIBERTAD EN COLOMBIA*
}

\section{The human rights of prisoners in Colombia}

Luis Alfonso Fajardo Sánchez. Ph.D**

Recepción: 30 de junio de 2017. Aceptación: 30 de noviembre de 2017.

DOI: http://dx.doi.org/10.21017/Rev.Repub.2018.v24.a43

\section{RESUMEN}

El balance respecto de la garantía de los derechos humanos, en los centros penitenciarios y carcelarios de Colombia, es una situación poco alentadora, porque las personas privadas de la libertad en los centros penitenciarios del país sufren condiciones inhumanas. A pesar de los avances constitucionales y legales se mantiene la deuda histórica del Estado colombiano, respecto de la garantía de los derechos humanos de un grupo de personas, consideradas por la comunidad internacional, en condiciones de vulnerabilidad y bajo custodia del Estado. El Estado colombiano se ha mostrado incapaz de cumplir materialmente con lo ordenado por la Constitución y la reiterada Jurisprudencia De la Corte Constitucional sobre la garantía de los derechos de esta población privada de la libertad. El artículo hace un estudio respecto de varias modalidades de tortura y tratos crueles, inhumanos y degradantes vividos permanentemente por las personas privadas de la libertad (PPL) y de las causas del aumento significativo de los casos de suicidio y muertes violentas de los reclusos en los centros carcelarios y penitenciarios del país.

Palabras clave: Derechos humanos, personas privadas de la libertad, estado de cosas inconstitucional, tortura, derechos de los reclusos.

* Artículo resultado del proyecto de investigación «El crimen de tortura en Colombia» del Grupo de investigación Consciencia: Estudios de Bioética, Ecología Humana y Ecología Política de la Facultad de Derecho de la Universidad Libre de Bogotá.

** Ph. D., posdoctor de la Universidad de Córdoba, Argentina. Doctor en Derecho, Universidad Carlos III de Madrid. Doctor en Ciencias Políticas y Sociología de la Universidad Complutense de Madrid, España. Magíster en Derecho de la Universidad Internacional de Andalucía, España. Miembro del Grupo de investigación Colciencias: Estudios de Bioética, Ecología Humana y Ecología Política de la Facultad de Derecho de la Universidad Libre de Bogotá. 


\begin{abstract}
ABTRACT
The balance sheet concerning the guarantees of the human rights, in the penitentiaries and prison centers of Colombia, is a non-encouraging situation; persons deprived of the freedom in the penitentiary centers of the country suffer inhuman conditions. In spite of the constitutional and legal advances remains the historical debt of Colombian State, respect the guarantees of human rights of a group of persons considered by the international community in conditions of vulnerability and under the custody of the State. Colombia has proved to be unable to materially abide with dispositions of by the Constitution, poliened which have been endorsed but the jurisprudence of this high tribunal, regarding the guarantees, of the human rights of the population deprived of freedom. The article contains a research about several forms of torture and cruel inhuman and degrading treatments permanently persons deprived of freedom and of the reasons significant increase of cases of suicide and violent deaths of prisoners in prison and penitentiary centers of the country.
\end{abstract}

Key words: Human rights, Persons deprived of the freedom, Unconstitutional State of Things, Torture, rights of the prisoners.

\title{
INTRODUCCIÓN
}

El Humanismo se ha convertido desde sus orígenes en una fuerza arrasadora, en la verdadera conciencia de la humanidad. El hombre quiere transformar el mundo por medio de la razón, la ciencia y la conciencia. La tríada más poderosa en la historia de la humanidad en la búsqueda de la Libertad, Igualdad y Solidaridad ha sido, en parte, posible por los avances del humanismo. La conciencia humana es el juez de nuestra época; este juez también nos interroga sobre las personas privadas de la libertad (PPL).

El marqués de Beccaria señalaba: «El fin de las penas no es atormentar y afligir a un ente sensible, ni deshacer un delito ya cometido» (Beccaria, 2013). En concordancia con esta afirmación, el Inpec tiene una consigna donde señala que a las cárceles y penitenciarias «entra la persona, no el delito». Sin embargo, la situación de miles de hombres y mujeres privados de la libertad en las prisiones colombianas es inhumana.

El Estado colombiano se ha mostrado incapaz de cumplir materialmente con lo ordenado por la Constitución y la reiterada Jurisprudencia de este alto tribunal sobre la garantía de los derechos de este sector social (Fajardo Sánchez, 2010). 
Para el presente artículo analizaremos los resultados de las encuestas, estudios de caso y testimonios realizados durante el desarrollo de la investigación realizada en los centros penitenciarios y carcelarios de 6 ciudades del pais (Bogotá, Cali, Bucaramanga, Barranquilla, Medellín y Pereira) sobre «Técnicas penitenciarias con Enfoque de Derechos Humanos». En la investigación participaron 170 funcionarios del Inpec, en su mayoría, miembros del Cuerpo de Custodia y Vigilancia. Las diferentes actividades de la investigación se realizaron durante el año 2015.

\section{PROBLEMA DE INVESTIGACIÓN}

El problema jurídico que surge a partir de la investigación es: ¿Se pueden evidenciar avances respecto de la garantía de los derechos humanos de las personas privadas de la libertad a partir de la generosa jurisprudencia de la Corte Constitucional sobre este tema?

\section{ESTRATEGIA METODOLÓGICA}

Se trata de una investigación basada en el método jurídico-analítico por el cual se desarrolla el análisis de la jurisprudencia. En un segundo momento se realiza un acercamiento socio-jurídico desde estudios de caso documentados de la realidad penitenciaria, resultado de las entrevistas, encuestas estudios de caso, encuestas, talleres y experiencias de 170 funcionarios del Instituto Nacional Penitenciario y Carcelario (Inpec) en los centros carcelarios y penitenciarios de seis (6) ciudades del país: Bogotá, Cali, Bucaramanga, Barranquilla, Medellín y Pereira.

\section{RESULTADOS}

\section{Nociones preliminares}

La denominación de «Estado Social de Derecho» describe a un estado garantista de los mínimos vitales de todos sus ciudadanos, incluidas las PPL, en cuanto a «salario, alimentación, salud, habitación, educación, asegurados para todos los ciudadanos bajo la idea de derecho y no simplemente de caridad (H. L. Wilensky, 1975).» (T406/1992).

En virtud del Artículo 93 de nuestra Carta magna, la incorporación de normas y principios del derecho internacional de los derechos humanos incursos en el "Bloque de Constitucionalidad" que en el caso de los derechos de las PPL estas normas y principios de origen internacional o supranacional han generado un 
interesante debate sobre el carácter vinculante de muchos de estos instrumentos. Por esta razón se ha creado una diferencia entre dos conceptos: el bloque de constitucionalidad «strictu sensu» y el «lato sensu».

«El primero se trata del strictu sensu, el cual se encuentra conformado por aquellos principios y normas de valor constitucional que se reducen al texto de la Constitución propiamente dicho y a los tratados internacionales que consagren derechos humanos cuya limitación se encuentre prohibida durante los estados de excepción (C. P., Artículo 93). El segundo es el lato sensu, el cual está compuesto por todas aquellas normas, de diversa jerarquía, que sirven como parámetro para efectuar el control de constitucionalidad» (Olaya, 2012).

En este sentido, la Corte Constitucional ha retomado muchos de estos instrumentos en sus sentencias, especialmente aquellas donde declaran un «Estado de Cosas Inconstitucional». Este tipo de sentencias se constituyen en la evidencia más contundente de la ausencia de un Estado Social de Derecho respecto de las PPL.

La declaratoria del Estado de Cosas Inconstitucionales según la propia jurisprudencia «es la declaratoria que hace la Corte Constitucional, cuando se constata la vulneración repetida y constante de derechos fundamentales que afectan a multitud de personas, cuya solución requiere la intervención de distintas entidades para atender problemas de orden estructural» (T-025 de 2004, 2004).

Otra de las características es su efecto erga omnes; es decir, estas sentencias de estado de cosas inconstitucionales tienen efecto para todas las personas que se encuentren en la misma situación, así no hayan interpuesto una acción de tutela (Fajardo Sánchez L., 2006, pág. 35).

La ausencia de las garantías mínimas constitucionales para las PPL en Colombia es muy grave; la evidencia más irrebatible la constituyen las cuatro sentencias de "estado de cosas inconstitucional" en los establecimientos carcelarios y penitenciarios: T-153/98, T-388/13, T-762/15 y T-197/17, la cual, a diferencia de las anteriores, si define de manera clara las competencias, los plazos y las entidades obligadas a actuar. Vamos a analizar algunos aspectos de esta última sentencia de 2013.

\section{Varios. «Estado de Cosas Inconstitucionales». Sentencia T-388/13}

La Corte en esta sentencia ha declarado nuevamente el «estado de cosas inconstitucional» en los centros penitenciarios de Colombia y menciona seis penales, los cuales, a juicio de la Corte Constitucional, poseen las más graves situaciones de hacinamiento y vulneración de derechos fundamentales de las PPL. 
Los seis establecimientos son: Complejo Carcelario y Penitenciario Metropolitano de Cúcuta, Cárcel La Tramacúa de Valledupar, Cárcel Modelo de Bogotá, Cárcel Nacional Bellavista de Medellín, Cárcel San Isidro de Popayán y Establecimiento penitenciario y carcelario de Barrancabermeja. En estos centros la situación de los internos es precaria, ya que sufren por las condiciones inhumanas y degradantes, altos niveles de hacinamiento, vulnerando la dignidad humana de manera sistemática.

La falta de acceso al derecho a la salud, alimentación adecuada y suficiente y, en general, negación del «mínimo vital»; requisas degradantes y humillantes; condiciones inhumanas de vida en el hacinamiento y temperaturas extremas son algunas de las problemáticas graves contra los derechos fundamentales de las PPL. Además de lo anterior, la vulneración del derecho al acceso a la justicia sumada a estas situaciones ha desencadenado un "estado de emergencia carcelaria» donde el Defensor del Pueblo, entre otros órganos de control, les exigen a las autoridades, con facultad y competencia en el tema, ejercer de manera eficiente su labor.

La Corte Constitucional, en la sentencia T-388 de 2013, al declarar por cuarta vez el estado de cosas inconstitucional en las cárceles del país, señala la violación de los derechos de manera sistemática, masiva y generalizada, en donde se han institucionalizado todo tipo de actuaciones inconstitucionales. Ordena la urgente creación de políticas carcelarias y penitenciarias además de la necesaria y urgente intervención de las entidades para subsanar la crisis: «Un Estado social y democrático de derecho, bajo ninguna circunstancia, puede imponer barreras u obstáculos infranqueables o considerables al acceso a los servicios de salud de las personas privadas de la libertad.» (Sentencia T-388/2013).

Todas las actuaciones del Estado para con las personas privadas de la libertad (PPL) deben estar enmarcadas en el respeto de su dignidad humana (Constitución Política de Colombia, 1991). La Jurisprudencia de la Corte Constitucional sobre este particular ha sido generosa, como lo menciona la Sentencia T-762/ 14, donde afirma: «El Tribunal se refiere a la sentencia T-501 de 1994 de la Corte Constitucional [...] una infraestructura adecuada que permita, tanto a los internos como a quienes a cualquier título permanezcan allí, convivir en circunstancias acordes con la dignidad humana» (T-762/14). El Estado como garante de los derechos de las PPL debe otorgarles todas las condiciones necesarias, permitiendo que las PPL puedan ejercer los derechos consagrados en la Carta Magna; así, de esta mane$\mathrm{ra}$, los reclusos y reclusas pueden realizar su plan de vida como lo menciona la sentencia T-881/02 (T-881/02, 2002).

Analicemos cómo cumple el Estado colombiano su deber de respeto de la dignidad humana de los internos e internas, casi 120.000 seres humanos, hombres 
y mujeres, recluidos en las 138 cárceles y penitenciarías del país. Como estudio de caso consideramos solo uno de los múltiples hechos totalmente indignos a los cuales se somete a los internos regularmente; hablamos de las llamadas Unidades de Tratamiento Especial (UTE).

\section{Los castigos de aislamiento}

La Circular 003 de 2010 del Inpec establece las «Pautas para el Manejo y Atención de Internos en las Unidades de Tratamiento Especial (UTE)»; las define como «Espacios destinados a alojar temporalmente, con el objeto de estabilizar a internos con dificultades de carácter sanitario, psicológico, o de seguridad, de conformidad con los artículos 123, 125 y 126 de la Ley 65 de 1993 y por un tiempo estrictamente necesario». (Inpec, Directiva 003, 2010). Sin embargo, en la práctica, las medidas UTE son utilizadas, de acuerdo a los casos presentados por los funcionarios del Inpec entrevistados en el marco de la investigación; dichas medidas se aplican de manera indiscriminada, desproporcionada y por largos periodos de tiempo, especialmente a los «internos conflictivos o problemáticos; a los psiquiátricos y a los que no aceptan en ningún otro patio» (Fajardo Sánchez L. A., 2016).

De la misma manera, la Directiva Permanente 23 de 2011, «Criterios para la ubicación de internos en las Unidades de Tratamiento Especial (UTE)» establece de manera clara el procedimiento y se reitera que esta medida debe ser tomada por la Junta de Asignación de Patios, motivada, fundamentada y legalizada por el cuerpo colegiado. Esta reiteración se hace con el objetivo de tomar la decisión por medio de este cuerpo interdisciplinario compuesto por «el director quien la preside, el subdirector, el asesor jurídico, el jefe de sanidad, el comandante de vigilancia y el trabajador social o el psicólogo» (Inpec, Directiva Permanente 23 de 2011, 2011).

La Ley 65 de 1993 establece en su artículo 81. de manera imperativa: «Por ningún motivo y sin excepción alguna, se asignará pabellón o celda por mecanismo diferente del señalado en este reglamento» (Congreso de la República de Colombia, 1993). Desafortunadamente, en la práctica funciona de manera diferente; de acuerdo con los Estudios de Caso relatados durante los 6 Talleres, realizados en el marco de la investigación en el año 2015, se puede concluir que en muchas ocasiones, son los Comandantes de Vigilancia quienes toman la medida UTE y luego consiguen la firma de los demás miembros de la Junta de Asignación de Patios; a esta práctica la llaman «legalizar» la decisión.

De los Estudios de Caso presentados por los funcionarios participantes de la investigación, se concluye: «las UTE, en muchas ocasiones, son utilizadas como una forma de "archivar" a los internos. Este término "archivar" es utilizado en el argot penitenciario, tanto por el personal del Cuerpo de Custodia y Vigilancia como por los 
mismos internos. Un interno llevado a la UTE es una persona a la cual se le limitan, en la mayoría de los casos, todas las posibilidades de recibir visitas, de realizar actividades de redención de pena (estudio o trabajo) sus condiciones de alimentación, sanitarias, salubridad etc., las condiciones de las UTE son extremadamente precarias. Utilizar las UTE de manera desproporcionada e irracional como mecanismo para "archivar" a los internos e internas, los deshumaniza al punto de vulnerar no solo todos sus derechos fundamentales, además su autoestima y sus deseos de vivir. Las UTE, son en muchos casos, uno de los motivos de suicidio o intento de suicidio» (Fajardo Sánchez L. A., 2016).

El defensor del pueblo ha informado en 2014 que en la mayoría de UTE del país se encontraron fallas graves en los sistemas de iluminación y ventilación, ausencia de agua potable permanente, techos enmugrecidos, pisos deteriorados, instalaciones eléctricas deficientes, así como brotes de infección en la piel diagnosticados bajo una enfermedad conocida como escabiosis (Defensoría del Pueblo, 2014).

Se documentaron casos como los del interno Pedro Luis Lozano, quien después de seis meses en la UTE del Establecimiento Penitenciario y Carcelario de Palogordo, Santander, decidió quitarse la vida el 21 de agosto de 2015. Un alto porcentaje de conductas suicidas se presenta en las UTE de todo el país (Fajardo Sánchez L. A., 2016).

\section{La muerte habita en los centros carcelarios y penitenciarios del país}

El Artículo 11 de la Constitución Política de Colombia establece la inviolabilidad del derecho a la vida en toda la nación. Este derecho se ha categorizado como un derecho incólume, también para las personas privadas de la libertad; por ende, es inviolable y no se puede limitar en ningún caso. La sentencia T-611/00 enfatiza en la existencia de una serie de derechos no limitables, que se mantienen incólumes, como es el derecho a la vida y la integridad física, «el poder disciplinario, cuyos límites están determinados, a su vez, por el reconocimiento de los derechos de los internos y por los correspondientes derechos estatales que se derivan de dicho reconocimiento, todo lo cual significa que, aunque al interno le asiste la facultad de ser recluido en un lugar que le garantice la vida y la integridad física »(T-611/00).

La Corte Constitucional señala en la misma sentencia: «la autoridad encargada por la ley de la custodia y cuidados de los procesados y de velar por su integridad física y su vida, determinó en su momento, que el traslado del interno lo fuera al centro de reclusión del sitio, que ofreciera mayores condiciones de seguridad».(T611/00). La responsabilidad del Estado en la garantía del derecho a la vida y la integridad física de los reclusos y reclusas es totalmente incuestionable, la condición de especial sujeción de las PPL con el Estado y su condición 
de grupo en condiciones de vulnerabilidad obligan al Estado a implementar todas las medidas eficaces y urgentes para garantizar, entre otros muchos, estos dos derechos.

La Constitución de 1991 prohíbe de manera clara y taxativa en su artículo 12 los tratos crueles e inhumanos o degradantes a cualquier persona: «Nadie será sometido a desaparición forzada, a torturas ni a tratos o penas crueles, inhumanas o degradantes» (Constitución Política de Colombia, 1991). Igualmente, el Estado colombiano, mediante la Ley 70 de 1986, ratifica la Convención internacional contra la tortura y otros tratos o penas crueles, inhumanas y degradantes; así, dicha Convención ha sido incorporada por el Estado colombiano, a su Bloque de Constitucionalidad.

La Jurisprudencia de la Corte Constitucional, reafirmando la prohibición total de realizar cualquier acto de tortura o trato cruel inhumano o degradante, ha sido «gigante» y generosa ; por ejemplo, en la Sentencia T-282/14, el Alto Tribunal reitera: «La prohibición de la tortura y otros tratos o penas crueles, inhumanos o degradantes, genera en cabeza del Estado colombiano una serie de responsabilidades, de prevención pero también de investigación y garantías de no repetición frente a las víctimas» (T-282/14).

Igualmente, la Sentencia C-351/98 señala: «Ha recordado la Corte que el objetivo de prevenir y sancionar la tortura, se erige para los Estados y las sociedades democráticas en un imperativo ético y jurídico, en tanto dicha práctica contradice la condición esencial de dignidad del ser humano, su naturaleza y los derechos fundamentales que se predican inherentes a la misma, por lo que la misma está expresamente proscrita en el ordenamiento internacional» (Sentencia C-351/98, 1998).

Uno de los pocos casos en el cual se condena a funcionarios del Inpec a penas privativas de la libertad fue la muerte del interno LUIS FERNANDO PRECIADO OSORIO, quien, de acuerdo a la sentencia del Juzgado Cuarto Penal del Circuito de Valledupar del 2 de julio de 2004, fue "golpeado inhumana y salvajemente por el personal de guardianes que llevó a cabo el procedimien to (...) en el desarrollo de un procedimiento de "extracción de celda", causándole graves lesiones que determinaron su posterior muerte» (Sentencia del Juzgado Cuarto Penal del Circuito de Valledupar del 2 de Julio de 2004, 2004). En los hechos fueron condenados a más de 14 años de prisión siete (7) funcionarios del Inpec.

El Informe de la Coalición Colombiana Contra la Tortura de abril de 2014, afirma respecto de los casos de PPL que denunciaron haber sido lesionados o torturados: «Medicina Legal informa que entre el año 2010 y lo corrido del 2014 fueron valoradas 2.425 personas privadas de libertad por presentar lesiones personales, de las cuales 187 son mujeres y 7 pertenecen a la comunidad LGTBI. 
En contraste, la Fiscalía General de la Nación indica que existen 750 procesos en curso en contra de personal del Inpec, por las diferentes modalidades delictivas de las cuales 226 son por lesiones personales». (Coalición Colombiana Contra la Tortura, 2014).

Todos los funcionarios participantes en la investigación manifestaron respecto de sus compañeros, quienes usan de manera irracional la fuerza contra los reclusos, quienes están plenamente identificados, que incluso han sido en varias ocasiones denunciados por sus propios compañeros o los «cuadros de mando», pero estas investigaciones disciplinarias, en opinión de los asistentes, nunca terminan en una sanción, y estos funcionarios violentos aún están en sus cargos e incluso se han vuelto más violentos que antes de las denuncias (Fajardo Sánchez L. A., 2016).

Las Observaciones Finales sobre el Quinto Informe periódico de Colombia realizadas por el Comité Contra la Tortura de la ONU en mayo de 2015 señalan sobre el deber del Estado frente a los presuntos hechos de tortura realizados por agentes de este mismo:

\begin{abstract}
«El Estado parte debe garantizar que todas las denuncias relacionadas con el uso excesivo de la fuerza por agentes del orden y personal militar sean investigadas con prontitud, eficacia e imparcialidad, y velar por que los presuntos autores sean enjuiciados, y de ser condenados culpables, sancionados de conformidad con la gravedad de sus actos. Debe velar también por que las víctimas o sus familiares reciban una reparación adecuada. Además, el Estado parte debe capacitar adecuadamente a todos los agentes del orden sobre el uso de la fuerza y regular el uso de las armas de fuego por las fuerzas de seguridad conforme a los Principios básicos de las Naciones Unidas sobre el empleo de la fuerza y las armas de fuego por los funcionarios encargados de hacer cumplir la ley (1990)» (Comité Contra la Tortura, 2015).
\end{abstract}

El 30 de enero de 2015 la Comisión Interamericana de Derechos Humanos solicitó al Estado colombiano, mediante Resolución 3 de 2015, la adopción urgente de «medidas cautelares » en favor de José Ángel Parra Bernal para preservar su vida e integridad personal por falta de la debida atención médica a su enfermedad denominada «leucemia mieloide crónica». El señor Parra Bernal se encuentra recluido en el Establecimiento Penitenciario de Mediana y Alta Seguridad «La Picota» en la ciudad de Bogotá (CIDH, 2015).

A pesar de contar con una tutela a su favor, el Estado colombiano nunca cumplió con su deber de proteger la vida y la integridad del señor Parra Bernal, ocasionándole graves dolores y sufrimientos. De acuerdo con la jurisprudencia de la Corte Interamericana de Derechos Humanos, siendo la causa de estas dolencias 
la omisión por parte del Estado de sus obligaciones de garante de los derechos humanos de las PPL en centros penitenciarios o carcelarios, estos hechos pueden ser constitutivos de tortura. Como este caso existen miles de situaciones similares; en muchas ocasiones los internos mueren de «causa natural» debido a la ausencia de atención médica o sanitaria (Fajardo Sánchez, 2010).

El 27 de agosto de 2014, la Organización Mundial Contra la Tortura (OMCT) llevó a cabo una visita en el Establecimiento Penitenciario y Carcelario de Alta y Mediana Seguridad de Valledupar y denunció la grave situación de salud del interno Aris Alberto Carrillo, porque su vida se hallaba en peligro debido a que desde hacía casi un año requería tratamiento médico urgente y especializado a causa de una osteomielitis, derivada de la falta de atención poshospitalaria adecuada (OMCT, 2014).

El Derecho a la vida de los reclusos y reclusas colombianos es un derecho en permanente amenaza. Según los datos reportados por el Centro Estratégico de Información Penitenciaria (Cedip) del Inpec, durante los años 2013 al 2015 murieron 1255 internos e internas de «causas naturales»; no fue posible determinar a partir de este dato, cuáles de estas muertes «naturales» se pudieron haber causado por inasistencia médica oportuna, error de diagnóstico, negligencia médica, o como fruto de un hecho de uso irracional de la fuerza (Cedip, 2015).

Igualmente, el Centro Estratégico de Información Penitenciara (Cedip) nos informa, por medio de la siguiente gráfica, que durante los años 2012 a 2015 murieron 157 internos por armas de fuego (Cedip, 2015). Ver figura 1.

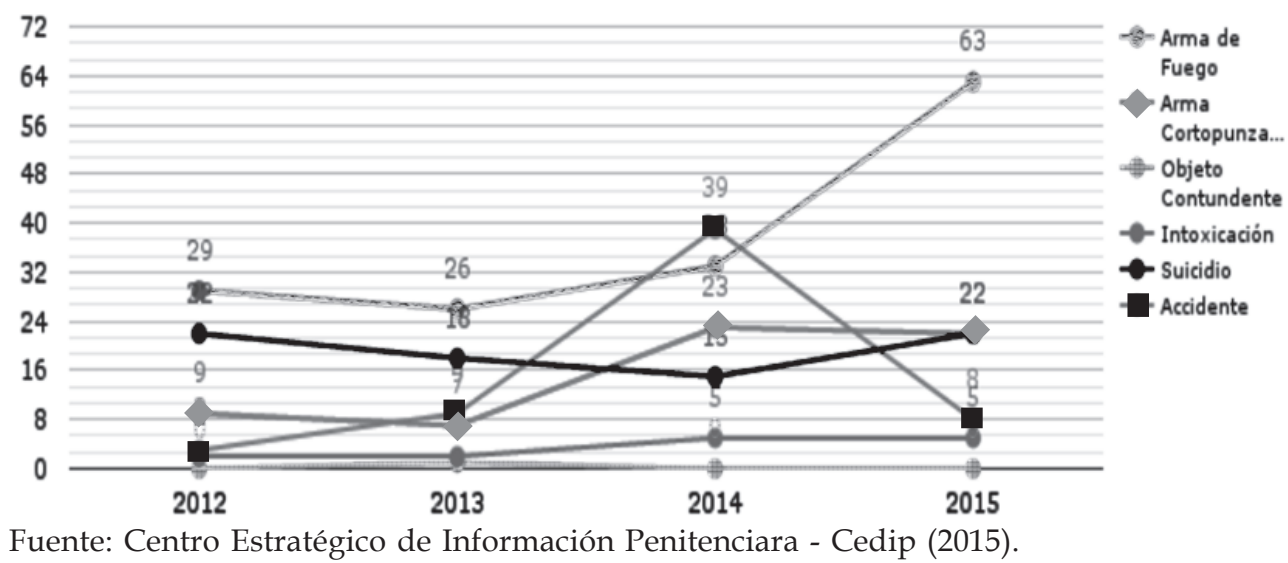

Figura 1. Demás causas o modalidades de fallecimientos de internos. 
Estas cifras nos deben generar preocupación; especialmente el Inpec debería explicar el aumento del $162 \%$ de los casos de internos o internas muertas por armas de fuego el año 2015 en relación con el año 2014.

\section{El gobierno de facto en los patios de los centros carcelarios y penitenciarios del país}

Analicemos ahora, uno de los factores de mayor incidencia en la vida cotidiana de los patios de los centros penitenciarios y carcelarios del país; el gran poder de los llamados «jefes de patio», «caciques» $\mathrm{O}$ «plumas».

Cada patio tiene su «gobierno» interno y funciona de la manera más violenta. Los internos con escasos recursos, sin medios económicos o con familias pobres sin capacidad económica para apoyarlos, no pueden sufragar estos costos; entonces deben someterse a pagar de muchas maneras inhumanas, incluso siendo sometidos a violación sexual o convirtiéndose en cómplices o autores de los delitos cometidos por los «caciques» dentro y fuera de los establecimientos de reclusión.

Incluso en la práctica, el proceso de inducción al interno o interna nueva, que debería realizarlo el Comandante de Vigilancia, como lo ordena la Ley, en la mayoría de las veces lo realiza el llamado «pluma»o «cacique»; de esta manera inicia la situación de subordinación el nuevo interno al poder del «jefe del patio». El momento del ingreso es fundamental porque en ese proceso, el interno conoce el reglamento interno, sus derechos, días y horas de visita, etc.; si en la práctica, esta inducción se delega al interno con más poder en el patio, el Estado está omitiendo esta obligación, colocando al interno o interna nuevo en manos del cacique, con todas las implicaciones negativas para el recluso recién llegado (Fajardo Sánchez L. A., 2016).

La Sentencia T-388 de 2013 hace alusión directa a esta crítica situación: «La prensa, al igual que los escritos académicos, ha mostrado como las personas recluidas en penitenciarías y cárceles tienen que pagar por todo. Conseguir un buen lugar en un pasillo tiene sus costos; conseguir una celda es prácticamente imposible, sobre todo por su altísimo valor. Diferentes analistas de la realidad nacional, en diversos medios de comunicación, han puesto de presente su opinión al respecto».

Todo aquello que el Estado tiene la obligación de entregar al interno y no lo hace, se convierte en objeto de tráfico en la prisión. Por ejemplo el kit de limpieza (1 tubo de pasta de dientes, 1 rollo de papel higiénico, 1 desodorante, 1 jabón); este debe ser entregado máximo cada tres meses, pero en la realidad, con suerte se entrega dos veces al año; la colchoneta debe ser entregada a cada 
interno al momento del ingreso, pero en muchas ocasiones no se entrega. Obtener un sitio donde dormir es un privilegio que cuesta; una llamada telefóni$\mathrm{ca}$, un paquete de cigarrillos, etc.

"Los internos e internas sin recursos para pagar a los "caciques" se ven sometidos a todo tipo de tratos crueles inhumanos y degradantes, a violencia sexual o se convierten en los llamados "carritos" o "jibaros" es decir, aquellos internos o internas que transportan elementos ilegales, drogase incluso armas de patio a patio, lo internos más pobres para "pagar" sus deudas terminan involucrando a sus familiares en acciones delictivas, fuera del penal.

En el lenguaje carcelario, muchas veces deshumanizante, a los internos más pobres los llaman "los arrastrados". Para estos seres humanos, bajo custodia del Estado, de un Estado que no les garantiza ni el mínimo vital, el suicidio se pasea permanentemente por su mente...» (Fajardo Sánchez L. A., 2016).

La Corte Constitucional en sentencia T- 388 de 2013 también analiza este tema respecto de los poderes de facto de los llamados caciques:

"Algunos autores resaltan que una persona, al ser privada de la libertad, se enfrenta a un sistema de control y sujeción disciplinaria que implica, muchas veces, que las reglas y limites pierden su carácter escrito y se confunden con la voluntad del guardia encargado. En Colombia, muchas de estas reglas provienen, desafortunadamente, de poderes paralelos como los caciques del patio, o actores ilegales del conflicto, que imponen, de facto, limitaciones y restricciones irrazonables y desproporcionadas al goce efectivo de los derechos fundamentales» (Corte Constitucional de Colombia, 2013).

\section{Derecho a presentar peticiones respetuosas}

«Toda persona tiene derecho a presentar peticiones respetuosas a las autoridades por motivos de interés general o particular y a obtener pronta resolución». (Constitución Política de Colombia, 1991).

Finalmente, como se menciona en la Constitución de 1991, «El legislador podrá reglamentar su ejercicio ante organizaciones privadas para garantizar los derechos fundamentales» (Constitución Política de Colombia, 1991); el artículo menciona «todos», refiriéndose también a las personas privadas de la libertad, quienes tienen el derecho de realizar peticiones a las autoridades, como el Inpec, las EPS, los jueces de ejecución de penas, el Ministerio de Educación Nacional, el Sena, etc. «La jurisprudencia constitucional ha manifestado que el derecho de petición de los internos es una de las garantías que no tiene ningún tipo de limitaciones en razón a la 
condición en que se encuentran» (Sentencia T-266/13). El derecho a hacer peticiones no se debe ver limitado; por ende, es uno de los derechos incólumes de las PPL, y el Estado debe garantizarse su acceso.

Igualmente, la Corte Constitucional ha fijado unas pautas para proteger dicho derecho de manera plena, señalando los deberes del Estado: «(i) Dar una completa, pronta y adecuada respuesta, evitando demoras injustificadas. (ii) La contestación debe contener una motivación razonable, y en el evento de no ser posible responder en el término legal se tiene que justificar el retraso. (iii) En cuanto a solicitudes de beneficios administrativos, tanto los centros de reclusión como los jueces deben dar respuesta en los plazos consagrados por la ley. (iv) Garantizar que las peticiones elevadas por los reclusos contra otras autoridades sean recibidas por estas oportunamente. (v) Si quien recibe la solicitud no tiene competencia para resolverla, tiene que remitir los documentos pertinentes al órgano o funcionario competente» (Sentencia T-266/13).

En el mismo sentido, se analizaron 15 casos donde los establecimientos de reclusión han sido compelidos, mediante fallos de tutela, a responder, en los términos definidos por la Corte Constitucional, a los derechos de petición de los internos e internas (Mouthón, 2014).

La mayoría de derechos de petición invocados por los internos e internas se refieren a temas como salud, hacinamiento, cómputos en la redención de penas, beneficios penitenciarios, alimentación, uso desproporcionado de la fuerza, visitas, etc. (Fajardo Sánchez, 2010). El incumplimiento del derecho de petición por parte del Estado a las PPL, y la falta de soluciones reales y eficaces, puede tener como consecuencia, en algunos casos, la utilización de medios de protesta, por parte de los reclusos, como los amotinamientos, utilizados por los internos e internas para el cumplimiento efectivo de sus derechos fundamentales.

Según las cifras reportadas por el Inpec, que sirvieron de insumo para el desarrollo de la investigación, durante los años 2008 al 2014 se presentaron a nivel nacional 117 situaciones de motín (Inpec, 1381, 2014):

\begin{tabular}{lccccccc}
\hline Año $^{1}$ & 2014 & 2013 & 2012 & 2011 & 2010 & 2009 & 2008 \\
\hline Total: & 10 & 15 & 34 & 23 & 15 & 11 & 9 \\
\hline
\end{tabular}

Para entender el alto número de presuntos «amotinamientos», en el marco de la investigación, se incluyeron preguntas sobre este particular en las encuestas

1 Respuesta Inpec nro. 1381 de julio de 2014. 
aplicadas a los 170 funcionarios del Inpec; estos son algunos de los resultados. Figura 2.

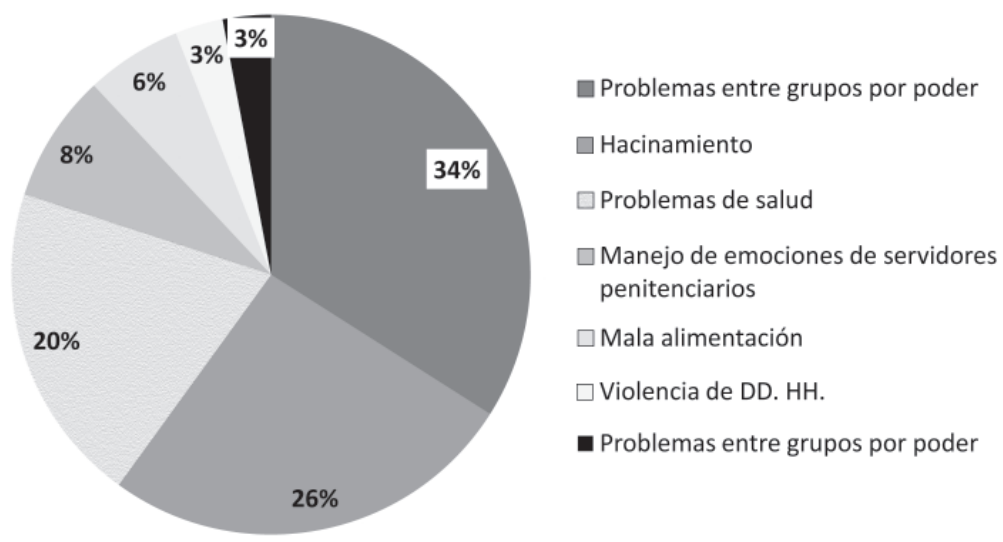

Figura 2. ¿Cuáles cree usted que son las causas más frecuentes de los motines?

La manera violenta con la cual los Grupos de Reacción Inmediata (GRI) enfrentan cualquier tipo de protesta por parte de los reclusos ha dejado una cifra aún indeterminada de internos muertos o heridos; para poder tener una idea aproximada de los resultados de estas intervenciones analizamos una muestra de 10 casos documentados en el desarrollo de la investigación a partir de trabajo de archivo y entrevistas con funcionarios del Inpec.

\begin{tabular}{lcc}
\hline & $\begin{array}{c}\text { Base de datos de la muestra } \\
\text { obtenida de los estudios de } \\
\text { caso analizados durante la } \\
\text { investigación }\end{array}$ & Datos informados por INPEC. \\
\hline Amotinamientos & 10 & 117 \\
\hline $\begin{array}{l}\text { Internos muertos en } \\
\text { los amotinamientos }\end{array}$ & 19 & $\begin{array}{l}\text { «No se cuenta con los registros, } \\
\text { ya que las estadísticas que se rea- } \\
\text { lizan en el instituto son concep- } \\
\text { tos y registros generales».2 }\end{array}$ \\
\hline $\begin{array}{l}\text { Internos heridos en } \\
\text { los amotinamientos }\end{array}$ & 221 & $\begin{array}{l}\text { «No se cuentan con los registros, } \\
\text { ya que las estadísticas que se rea- } \\
\text { lizan en el instituto son concep- } \\
\text { tos y registros generales». }\end{array}$ \\
\hline Internos fugados & 2 & \\
\hline
\end{tabular}

2 Respuesta Inpec nro. 1381 del 1 de julio de 2014.

3 Respuesta Inpec nro. 1381 del 1 de julio de 2014. 
La muestra es de casi el 10\% de los casos reportados por el Inpec. Es una muestra significativa, cuyo resultado es que en 10 casos de los 117 reportados, murieron 19 internos y fueron heridos 221. Sin embargo, no debemos apresurar conclusiones sobre este particular hasta realizar estudios más detallados. Pero estos resultados no dejan de ser altamente preocupantes.

No fue posible que el Inpec nos informara el número de estos reclusos o reclusas muertas por armas de fuego en desarrollo de operaciones de control de protestas, motines u otras formas de alteración del orden interno penitenciario. Si no existen datos respecto a los internos heridos o muertos durante los disturbios o motines, es realmente incomprensible ; porque de acuerdo con los procedimientos establecidos por esta misma institución, el comandante de la guardia, quien debía dirigir directamente estas operaciones, tiene la obligación de elaborar un informe detallado después de cada uno de los hechos graves de disturbios o amotinamientos; es decir, si no existen datos es porque no se ha cumplido con esta orden, lo cual sería muy grave. Si no existe un criterio en el Cedip para registrar la información de internos o internas muertas o heridos en operativos antimotines, hay que crearlo con urgencia.

\section{CONCLUSIONES}

Los avances respecto de la garantía de los derechos de las PPL en Colombia son pocos. La crisis penitenciaria y carcelaria ya es endémica. A pesar de las sentencias de la Corte Constitucional colombiana y de la misma normatividad, la situación de las prisiones del país se agrava cada vez más.

Esta crisis no parece tener una solución a corto plazo, ni a mediano ni largo; así lo señalaron las sentencias 388 de 2013 y T-762 de 2015, donde además se ordena la creación de un mecanismo de seguimiento en cabeza de la Defensoría del Pueblo para garantizar el cumplimiento de estos fallos y verificar el mejoramiento de la situación de las PPL.

Respecto del derecho a la vida se debe recordar al cuerpo de custodia y vigilancia del Inpec que la pena de muerte no existe en Colombia. Los internos que protestan en un patio, incluso realizando acciones violentas, están en estado de inferioridad frente al personal del cuerpo de custodia y vigilancia armado y ubicado en las garitas o en sitios estratégicos del establecimiento. Se analizaron casos donde el uso de gases ha sido suficiente para reducir a los internos amotinados sin necesidad de utilizar las armas de fuego.

Desde la sociedad civil tenemos la obligación de hacer seguimiento a estos fallos para evitar su desacato, como ha sucedido en muchos casos. Por este 
motivo se creó en el año 2015 la Comisión de Seguimiento a las sentencias 388 de 2013 y la T 762/15. En esta comisión hacemos parte universidades, ONG, expertos en el tema, exmagistrados de las altas cortes, etc. Esperemos que este nuevo mecanismo coadyuve a la solución de esta crisis estructural y sistemática y por fin el humanismo proclamado por Beccaria llegue a nuestro país, con tres siglos de retraso.

\section{REFERENCIAS}

Asamblea Nacional Constituyente. (1991). Constitucion Política de Colombia. Obtenido de www.alcaldia.com.co

Asamblea General ONU. (9 de diciembre de 1985). Convención Interamericana para prevenir y sancionar la tortura. Obtenido de adoptada en Cartagena de Indias, Colombia.

Asamblea General ONU. (18 de diciembre de 2002). Protocolo facultativo de la Convención contra la tortura y otros tratos o penas crueles, inhumanos o degradantes. Obtenido de adoptada por Resolución 77/199.

Asamblea General ONU. (17 de diciembre de 1979). Código de conducta para funcionarios encargados de hacer cumplir la ley. Obtenido de adoptado por resolución 34/169.

Beccaria, C. (2013). De los delitos y las penas. Bogotá: Temis.

Cedip. (2015). Informe de internos fallecidos en las cárceles y penitenciarías de Colombia 2013-2015. Bogotá: Inpec.

CIDH. (2015). Resolución 3 de 2015.

Coalición Colombiana contra la Tortura. (2014). Situación de tortura en Colombia. Bogotá: Comisión Colombiana de Juristas.

Comité Contra la Tortura. (2015). Observaciones finales sobre el Quinto informe periódico de Colombia. Ginebra, Suiza: ONU.

Congreso de la República de Colombia. (1993). Ley 65 de 1993. Recuperado el 2016, de www.alcaldia.gov.co

Corte Constitucional Colombiana. (1998). Sentencia C-351/98. Obtenido de http:// www.corteconstitucional.gov.co/relatoria/1998/C-351-98.htm

Corte Constitucional de Colombia. (2015). Sentencia T-762/15. Obtenido de http:/ / www.corteconstitucional.gov.co/?bSo 
Corte Constitucional de Colombia. (1992). T-406/1992. Obtenido de Estado Social de Derecho: http:/ / www.corteconstitucional.gov.co/relatoria/1992/T-533-92.htm

Corte Constitucional de Colombia. (2000). T-611/00. Obtenido de Derecho a la vida de las personas privadas de la libertad, traslados por cuestiones de seguridad: www.corteconstitucional.gov.co

Corte Constitucional de Colombia. (2002). T-881/02. Obtenido de Dignidad humana: www.corteconstitucional.gov.co

Corte Constitucional de Colombia. (2013). Sentencia T-266/13. Obtenido de www.corteconstitucional.gov.co

Corte Constitucional de Colombia. (2013). Sentencia T-388/2013. Obtenido de Estado de cosas inconstitucional carceles Colombianas: www.corteconstitucional.gov.co/ relatoria

Corte Constitucional de Colombia. (2014). T-282/14. Obtenido de Respeto por la dignidad humana de personas privadas de la libertad: www.corteconstitucional.gov.co

Corte Constitucional de Colombia. (Derecho fundamental a la salud frente a sujetos de especial protección-Nexo e importancia con los principios de integralidad y de continuidad). T-762/14. Obtenido de http://www.corteconstitucional.gov.co/ relatoria/2014/T-762-14.htm

Corte Constituconal de Colombia. (2004). T-025 de 2004. Obtenido de http:// www.corteconstitucional.gov.co/relatoria/2004/t-025-04.htm

Defensoría del Pueblo. (2014). Situación de Derechos Humanos de las personas privadas de la libertad en Colombia. Bogotá.

Fajardo Sánchez, L. (2006). Los invisibles y la lucha por el derecho en Colombia. Una mirada desde las casas de justicia. Bogotá: Universidad Santo Tomás.

Fajardo Sánchez, L. A. (2010). Beccaria está preso en la Cárcel Distrital. Un estudio de caso sobre el «Estado de Cosas Inconstitucionales» en los centros de reclusión de Colombia. IUSTA, 67-88.

Fajardo Sánchez, L. A. (2010). Los invisibles y la lucha por el derecho en Colombia. Una mirada desde las Casas de Justicia. Universidad Santo Tomás.

Fajardo Sánchez, L. A. (2016). Técnicas penitenciarias con enfoque de derechos humanos. Bogotá: Ministerio de Justicia y el Derecho, Unión Europea.

Inpec. (2008). Manual de Técnicas Penitenciarias. Bogotá: Inpec.

Inpec. (2010). Directiva 003. Bogotá, Colombia: Inpec. 
Inpec. (2011). Directiva Permanente 23 de marzo de 2011. Bogotá: Inpec.

Mouthón, L. Q. (21 de septiembre de 2014). Hacinamiento en la Cárcel La Ternera en Cartagena. El Universal de Cartagena.

Oficina del alto comisionado de las Naciones Unidas para los derechos humanos. (2007). ProtecciÓn de los derechos humanos de las personas privadas de la libertad. Bogotá: ONU.

Olaya, M. A. (2012). El bloque de constitucionalidad en la jurisprudencia de la Corte Constitucional Colombiana. Obtenido de http://www.icesi.edu.co/contenido/pdfs/C1Cmarango-bloque.pdf

OMCT. (2014). Informe visita en el Establecimiento Penitenciario y Carcelario de Alta y Mediana Seguridad de Valledupar. OMCT.

ONU. (1986). Convención contra la tortura y otros tratos o penas crueles, inhumanas o degradantes. Ginebra, Suiza: ONU.

ONU. (1990). Principios Básicos sobre el Empleo de la Fuerza y de Armas de Fuego por los Funcionarios Encargados de hacer cumplir la Ley. La Habana, Cuba.

Primer Congreso de las Naciones Unidas sobre Prevención del Delito y Tratamiento del Delincuente celebrado en Ginebra en 1955. (13 de mayo de 1977). Reglas mínimas para el tratamiento de los reclusos. Obtenido de aprobado por resolución 663C del Consejo EconÓmico y Social.

Quintero Lyons, J., Navarro Monterroza, A. M., \& Irina Meza, M. (2011). La figura del estado de cosas inconstitucional como mecanismo de protección de los derechos fundamentales de la población vulnerable en Colombia. Revista Jurídica Mario Alario D’Filipo, 69-80.

Sentencia del Juzgado Cuarto Penal del Circuito de Valledupar del 2 de julio de 2004 (Juzgado Cuarto Penal del Circuito de Valledupar, 2 de Julio de 2004). 